ARTICLE

https://doi.org/10.1038/s41467-019-10320-y

\title{
CD160 serves as a negative regulator of NKT cells in acute hepatic injury
}

Tae-Jin Kim¹,10, Gayoung Park²,10, Jeongmin Kim¹, Seon Ah Lim¹, Jiyoung Kim¹, Kyungtaek Im¹, Min Hwa Shin', Yang-Xin Fu (10 ${ }^{3}$, Maria-Luisa Del Rio ${ }^{4}$, Jose-Ignacio Rodriguez-Barbosa ${ }^{4}$, Cassian Yee ${ }^{5}$, Kyung-Suk Suh ${ }^{6}$, Seong-Jin $\mathrm{Kim}^{7}$, Sang-Jun Ha ${ }^{8}{ }^{8}$ \& Kyung-Mi Lee $\mathbb{B}^{1,5,9}$

CD160 and BTLA both bind to herpes virus entry mediator. Although a negative regulatory function of BTLA in natural killer T (NKT) cell activation has been reported, whether CD160 is also involved is unclear. By analyzing $\mathrm{CD}_{160^{-} /-}$mice and mixed bone marrow chimeras, we show that CD160 is not essential for NKT cell development. However, CD160-/- mice exhibit severe liver injury after in vivo challenge with $\alpha$-galactosylceramide ( $\alpha$-GalCer). Moreover, $\mathrm{CD}_{160}^{-/-}$mice are more susceptible to Concanavalin A challenge, and display elevated serum AST and ALT levels, hyperactivation of NKT cells, and enhanced IFN- $\gamma$, TNF, and IL-4 production. Lastly, inhibition of BTLA by anti-BTLA mAb aggravates $\alpha$-GalCerinduced hepatic injury in $\mathrm{CD}_{160^{-/}}$- mice, suggesting that both CD160 and BTLA serve as non-overlapping negative regulators of NKT cells. Our data thus implicate CD160 as a coinhibitory receptor that delivers antigen-dependent signals in NKT cells to dampen cytokine production during early innate immune activation.

\footnotetext{
${ }^{1}$ Department of Biochemistry and Molecular Biology, Korea University College of Medicine, Seoul 02841, Republic of Korea. ${ }^{2}$ Department of Medicine, Section of Dermatology, The University of Chicago, Chicago, IL 60637, USA. ${ }^{3}$ Department of Pathology, University of Texas Southwestern Medical Center, Dallas, TX 75390, USA. ${ }^{4}$ Transplantation Immunobiology Section, Institute of Biomedicine, University of Leon, Leon 24071, Spain. ${ }^{5}$ Department of Melanoma Medical Oncology and department of Immunology, UT MD Anderson Cancer Center, Houston, TX 77054, USA. ${ }^{6}$ Department of Surgery, Seoul National University College of Medicine, Seoul 03080, Republic of Korea. ${ }^{7}$ Precision Medicine Research Center, Advanced Institutes of Convergence Technology, Seoul National University, Suwon, Gyeonggi-do 16229, Republic of Korea. ${ }^{8}$ Department of Biochemistry, College of Life Science and Biotechnology, Yonsei University, Seoul 03722, Republic of Korea. ${ }^{9}$ Department of Biomedical Engineering, Center for Bio-Integrated Electronics, Simpson Querrey Institute for BioNanotechnology, Northwestern University, Evanston, IL 60208, USA. ${ }^{10}$ These authors contributed equally: Tae-Jin Kim, Gayoung Park. Correspondence and requests for materials should be addressed to S.-J.H. (email: sjha@yonsei.ac.kr) or to K.-M.L. (email: kyunglee@korea.ac.kr)
} 
C D160 is a glycosylphosphatidylinositol-anchored Ig domain protein that is expressed on almost all intestinal intraepithelial lymphocytes (IELs), $\gamma \delta \mathrm{T}$ (gamma delta $\mathrm{T}$ ) cells, NK (natural killer) cells, and a minor subset of $\mathrm{CD}^{+}$and $\mathrm{CD}^{+} \mathrm{T}$ cells ${ }^{1-3}$. CD160 has been shown to bind MHC Class I at low affinity and herpes virus entry mediator (HVEM) at high affinity, and shares its ligand HVEM with BTLA in both T cells and NK cells ${ }^{4,5}$. While activation of HVEM signaling by LIGHT, BTLA, or CD160 binding enhances Ag-induced T cell proliferation and cytokine production ${ }^{6-8}$, engagement of BTLA/CD160 by HVEM provides negative signals to T cells via BTLA/CD $160^{4,5}$. Furthermore, CD160 has been reported to be a marker for T cell exhaustion, and increased CD160 expression in CD8 ${ }^{+} \mathrm{T}$ cells is associated with $\mathrm{T}$ cell exhaustion in chronic viral infection models $^{9-11}$. In contrast, CD160 cross-linking by MHC ligands (HLA-C) co-stimulates CD8 ${ }^{+} \mathrm{T}$ cells and activates $\mathrm{NK}$ cell cytotoxicity and cytokine production ${ }^{12}$. Therefore, CD160 can function as both a co-activating and co-inhibitory receptor, depending on which receptor/ligand is operating in the context of neighboring interactions.

Innate-like NKT cells express the NK1.1 marker as well as other typical NK receptors. Upon stimulation through their TCR, they rapidly produce substantial amounts of cytokines. Unlike NK cells, NKT cells develop in the thymus and express a rearranged TCR, whereas most of the population expresses canonical Va14-Ja18 TCR $\alpha$ chains associated with V $\beta 8, \mathrm{~V} \beta 7$ or V $\beta 2^{13-15}$. The best-characterized population is a NKT set composed of $\alpha \beta$ T cells specific for microbial lipids presented by the MHC class Ilike CD1d molecule, which is expressed on antigen-presenting cells (APCs) including dendritic cells (DCs) and Kupffer cells $(\mathrm{KC})^{16}$. After stimulation with a CD1d-bound antigen, NKT cells produce large amounts of pro- and anti-inflammatory cytokines within hours ${ }^{17,18}$. Interleukin (IL)-2, interferon (IFN) $-\gamma$, and tumor necrosis factor (TNF)- $\alpha$ lead to a pro-inflammatory $\mathrm{T}$ helper 1 (Th1) response, while cytokines such as IL-4, IL-5, IL-6, IL-10, and IL-13 promote an immunoregulatory T helper 2 (Th2) response. Increasing evidence suggests that NKT cells are essential for microbial defense and the initiation of adaptive immune responses in regulating autoimmune responses.

Activation of NKT cells is triggered by ligation of the semiinvariant TCR along with an array of co-stimulatory (CD28, CD40L, CD70, OX40, and 41BB) and co-inhibitory receptors (CTLA-4, PD-L1, GITR, and BTLA). Although it has been established in vitro and in vivo that BTLA is expressed on NKT cells and functions as a negative regulator in early innate immune responses, the role of CD160 in NKT cells is not fully understood due to the lack of proper blocking reagents and genedeficient animal models.

Using CD160- ${ }^{-1-}$ mice and a mixed bone marrow chimera generated in a lethally irradiated WT host, we evaluate the role of CD160 in BTLA/HVEM interactions. Here, we present data showing that the CD160/HVEM signaling axis delivers a BTLAindependent negative signal to NKT cells in both $\alpha$-GalCer and Con A-induced acute hepatitis.

\section{Results}

a-GalCer stimulation causes upregulation of CD160 in vivo. We first analyzed the surface expression of CD160 on NKT cells isolated from the thymus, liver, and spleen of C57BL/6 mice by flow cytometry. NKT cells were gated according to previous reports ${ }^{19}$ and the expression of CD160 on CD $45^{+}$TCR $\beta^{+}$PBS57CD1d-Tetramer ${ }^{+}$NKT cells was analyzed in the primary and secondary lymphoid organs (Fig. 1a). NKT cells expressing surface CD160 comprised of $2.3 \pm 0.3 \%$ of cells in the thymus, $5.0 \pm$ $1.5 \%$ in the liver, and $11.5 \pm 1.9 \%$ in the spleen at naive status
(Fig. 1a). In an in vivo challenge of C57BL/6 mice with $\alpha$-GalCer, the percentage of CD160 ${ }^{+}$NKT cells increased from $5.0 \pm 1.5 \%$ to $61.2 \pm 7.7 \%$ in the liver and from $11.51 \pm 1.9$ to $47.7 \pm 3.7 \%$ in the spleen within $4 \mathrm{~h}$, with significantly increased MFI (Fig. 1a). In contrast, $\mathrm{CD} 4^{+} \mathrm{T}, \mathrm{CD}^{+} \mathrm{T}, \mathrm{B}$, and $\mathrm{NK}$ cells did not exhibit altered surface CD160 in this time frame (Fig. 1b). Interestingly, there was no specific upregulation in other co-stimulatory or coinhibitory receptors on NKT cells, including BTLA, HVEM, 41BB, PD-1, OX40, CD28, CTLA-4, and CD95 (Fig. 1c and Supplementary Fig. 1). These findings indicate that NKT cells specifically upregulate CD160 expression during a-GalCerinduced hepatitis, accompanied by their early inflammatory processes.

CD160 does not affect the development status of murine NKT cells. To determine the role of CD160 in the development of NKT cells, we examined the frequency and number of NKT cells in the blood, thymus, liver, and spleen in $\mathrm{CD}_{160^{-/}}$mice. When compared to WT mice, CD160-I- mice did not show any significant difference in the proportion of NKT cells in each organ tested (Fig. 2a). Furthermore, no changes in the developmental stages of NKT cells, defined by stage $0\left(\mathrm{CD} 24^{+} \mathrm{CD} 44^{-} \mathrm{NK} 1.1^{-}\right)$, stage $1\left(\mathrm{CD} 44^{\text {low }}, \mathrm{NK} 1.1^{-}\right)$, stage $2\left(\mathrm{CD} 44^{+}, \mathrm{NK} 1.1^{-}\right)$, and stage $3\left(\mathrm{CD} 44^{+}, \mathrm{NK} 1.1^{+}\right)^{20}$, were noted as compared to WT mice (Fig. 2b).

The transcription factor pro-myelocytic leukemia zinc finger (PLZF) is an early transcriptional regulator of NKT cell development ${ }^{21}$. We further analyzed NKT cell subsets using a combination of lineage-specific transcription factors, as described previously ${ }^{22}$. The combination of PLZF, T-bet, and ROR $\gamma \mathrm{t}$ separated NKT cells into three subsets that produced distinct cytokines $^{22}$. Using intracellular staining with Abs against PLZF,

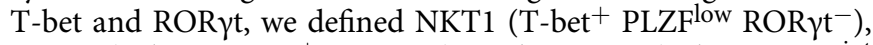
NKT2 (T-bet ${ }^{-}$PLZF $^{+}$ROR ${ }^{-}$), and NKT17 (T-bet ${ }^{-}$PLZFint ROR $\mathrm{t}^{+}$) cells by flow cytometry. The frequency and the absolute number of NKT1, NKT2, and NKT17 cells did not differ significantly between WT and CD160/- mice in the thymus or in the liver and spleen (Fig. 2c and Supplementary Fig. 2). Collectively, these findings indicate that CD160 is not essential for the development and differentiation of NKT cells.

$\mathrm{CD}_{160}^{-/-}$mice exhibit severe $\alpha-$ GalCer-induced liver injury. To test the role of CD160 in the regulation of NKT functions, we adopted $a$-GalCer-induced hepatitis mouse model, which resembles human autoimmune acute hepatitis ${ }^{23}$. Induction of hepatitis was evaluated in the liver tissues of WT and CD160-/mice by liver morphology study, H\&E staining and TUNEL assay at $24 \mathrm{~h}$ following $\mathrm{a}$-GalCer injection (Fig. 3a, b). CD160 ${ }^{-1-}$ mice demonstrated massive hepatic necrosis with elevated AST and ALT levels in serum (Fig. 3a-c) compared with WT mice. The serum levels of NKT-dependent cytokines IL-4, TNF- $\alpha$, and IFN$\gamma$ were significantly higher in $\mathrm{CD}_{160^{-1}}$ mice than in WT mice $2 \mathrm{~h}$ or $12 \mathrm{~h}$ following an $\mathrm{a}$-GalCer challenge (Fig. $3 \mathrm{~d}$ ). Increased tissue injury and elevated serum cytokines in $\mathrm{CD}_{160^{-/}}$mice were not found to be associated with elevated infiltration of $\mathrm{CD}_{11 \mathrm{C}^{+}} \mathrm{MHCII}^{+} \mathrm{DCs}, \mathrm{Ly}_{6 \mathrm{G}}{ }^{+} \mathrm{CD} 11 \mathrm{~b}^{+}$neutrophils, Ly6Chigh $\mathrm{CD}_{11 \mathrm{~b}^{+}}$monocytes, or F4/80 ${ }^{+} \mathrm{CD} 11 \mathrm{~b}^{+} \mathrm{Ly} 6 \mathrm{G}^{-}$Kupffer cells in the liver, as the percentages of these innate immune cells were comparable in $\mathrm{CD}_{160^{-1-}}$ mice and WT mice (Supplementary Fig. 3). Furthermore, the surface levels of CD160 ligand, HVEM (Supplementary Fig. 4), and CD40, CD1d, PD-L1, and CD80 (Supplementary Fig. 5) in liver MNCs were comparable in $\alpha$ GalCer-administered WT and $\mathrm{CD}_{160^{-/-}}$mice (Supplementary Fig. 5), suggesting that hyperactivation of NKT cells in CD160 mice was not likely due to changes in the expression of 


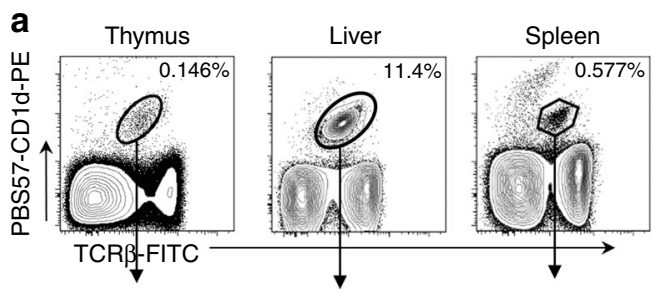

TCR $\beta^{+}$PBS57-CD1 ${ }^{+}$NKT cells
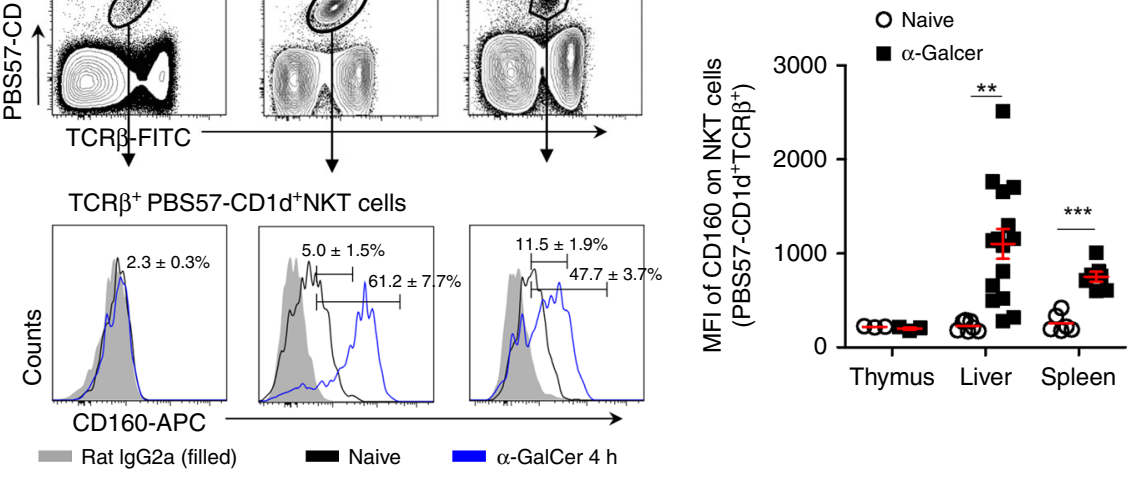

b

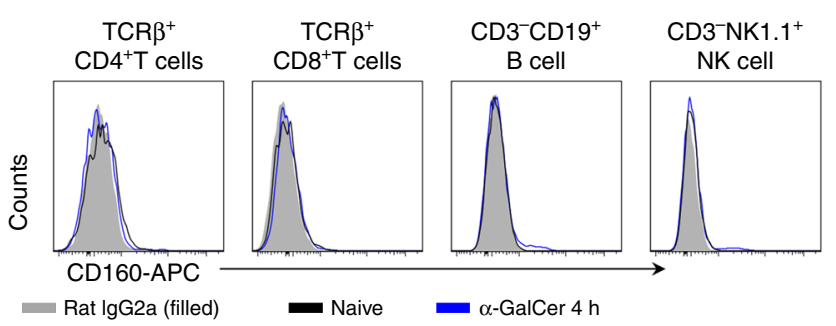

C

TCR ${ }^{+}$PBS57-CD1d ${ }^{+}$NKT cells in liver
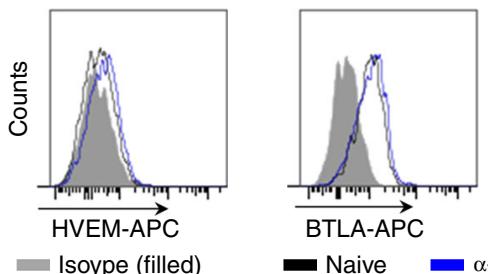

- Naive

$\alpha-$ GalCer $4 \mathrm{~h}$

Fig. 1 Upregulation of CD160 on NKT cells after $\alpha$-GalCer stimulation in vivo. a, b CD160 expression on NKT cells from the thymus, liver, and spleen $4 \mathrm{~h}$ before and after $\alpha$-GalCer challenge in vivo. Lymphocytes were stained with anti-TCR- $\beta$, PBS57-CD1d tetramer, and anti-CD160 APC mAb or control IgG. a Representative flow cytometry plots of CD160 expression and summary of the frequency of CD160 positivity in gated TCR $\beta^{+}$PBS57-CD1d tetramer ${ }^{+}$ from thymus, liver, and spleen NKT cells for $4 \mathrm{~h}$ before and after i.p. injection with $\alpha$-GalCer $(2 \mu \mathrm{g} / \mathrm{mice})$. The graph represents the mean florescence intensity of CD160 expression of NKT cells from the thymus, liver, and spleen ( $n=3-15$ per group). b Flow cytometry plots of CD160 expression in $\mathrm{TCR}^{+}{ }^{+} \mathrm{CD} 4^{+}, \mathrm{TCR}^{+}{ }^{+} \mathrm{CD} 8^{+}, \mathrm{CD}_{3}-\mathrm{CD} 19^{+}$, and $\mathrm{CD} 3^{-} \mathrm{NK} 11^{+}+$cells of liver MNCs $4 \mathrm{~h}$ before and after $\alpha$-GalCer injection. Results are representative of three independent experiments. $\mathbf{c}$ Representative flow cytometry plots of HVEM or BTLA expression in gated TCR $\beta^{+}$PBS57-CD1d tetramer ${ }^{+}$NKT cells from liver MNCs. All data are presented as mean \pm S.E.M. $n=3 .{ }^{\star} P<0.05,{ }^{\star \star} P<0.01,{ }^{\star \star \star} P<0.001$ with an unpaired two-tailed $T$-test

co-stimulatory or co-inhibitory receptors. These data indicate that CD160 normally acts in the early immune response by dampening cytokine production, thereby protecting against $\alpha$ GalCer-induced liver injury.

We next investigated whether CD160 regulates antigendependent signals downstream of a-GalCer presented on CD1d, not from other cell surface activating receptors. Therefore, we injected anti-CD1d mAbs $24 \mathrm{~h}$ prior to $\mathrm{a}$-GalCer injection to block CD1d-mediated signaling, and AST/ALT and related cytokine (IL-4, TNF- $\alpha$, IL- 6 , and IFN- $\gamma$ ) levels in the blood were measured in WT and $\mathrm{CD}_{160^{-l-}}$ mice. As shown in Fig. 3e, f, anti-CD1d mAb-treated $\mathrm{CD}_{160^{-1-}}$ mice demonstrated significantly decreased liver damage, showing reduced AST/ALT levels (Fig. 3e). Moreover, blocking CD1d abrogated $\alpha$-GalCer-induced cytokine secretion in both WT and $\mathrm{CD}_{160^{-1-}}$ mice (Fig. 3f), suggesting that CD160 specifically regulates $\alpha$-GalCer-induced NKT signals presented on CD1d.

Uncontrolled activation of the NKT cells in $\mathrm{CD160}^{-/-}$mice. To establish that the cytokines produced in $\mathrm{CD}_{160^{-/}}$mice by
a-GalCer were not coming from activated $\mathrm{CD}^{+}{ }^{+}$and $\mathrm{CD} 8^{+}$ $\mathrm{T}$ cells ${ }^{24}$, we injected mice with $\alpha-$ GalCer and isolated liver MNCs after $4 \mathrm{~h}$ for intracellular detection of IFN- $\gamma$. As seen in Fig. 4a, IFN- $\gamma$ expression was significantly increased on NKT cells, not $\mathrm{CD}^{+}$and $\mathrm{CD}^{+} \mathrm{T}$ cells, in response to $\alpha-$ GalCer (Fig. 4a). These results indicate that increased IFN- $\gamma$ in $\mathrm{CD}_{160}^{-/-}$mice during $\alpha$ GalCer-induced hepatitis was primarily due to activation of NKT cells, not $\mathrm{CD}^{+}{ }^{+}$or $\mathrm{CD}^{+}{ }^{+} \mathrm{T}$ cells.

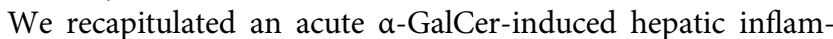
mation model in an in vitro setup with isolated liver MNCs to confirm the role of CD160. Liver MNCs were isolated from WT and $\mathrm{CD} 160^{-/-}$mice and stimulated with $\alpha$-GalCer for $24 \mathrm{~h}$ in vitro. NKT cells from $\mathrm{CD}_{160^{-/}}$mice secreted higher levels of IL-4, IFN- $\gamma$, and IL-17A than those of WT mice, consistent with our in vivo data (Fig. 4b). Similar results were obtained with splenocytes harvested from WT and CD160-I- mice, showing a time-dependent increase in IL-4, IFN- $\gamma$, and TNF- $\alpha$ up to $72 \mathrm{~h}$ (Fig. 4c). These findings suggest that CD160 receptors on NKT cells are crucial for regulating the production of inflammatory cytokines upon $a-$ GalCer stimulation. 

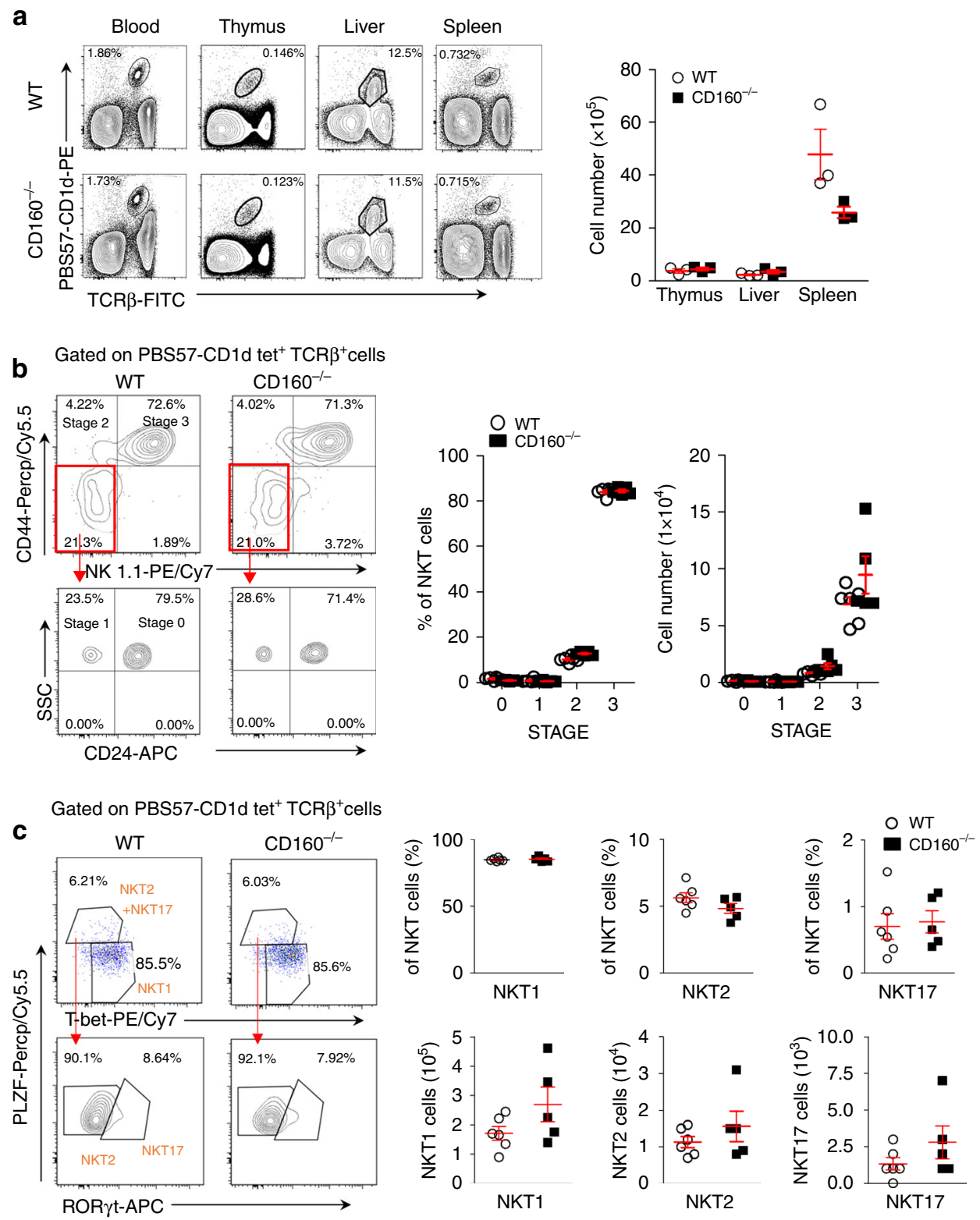

Fig. 2 Absence of CD160 does not affect the development of NKT cells. a Lymphocytes from blood, thymus, liver, and spleen in WT and CD160-/- mice were stained with anti-TCR $\beta$ FITC and PBS57-CD1d tetramer PE and analyzed by flow cytometry. Results are representative of three independent experiments. The absolute number of TCR $\beta^{+}$PBS57-CD1d Tetramer ${ }^{+}$NKT cells in the thymus, liver, and spleen was calculated based on the percentage of each population shown in ( $n=3$ per group). b Flow cytometry analysis of CD44 and NK1.1 expression among total NKT cells from the thymus of WT and $\mathrm{CD}_{160^{-/-}}$mice. Results are representative of three independent experiments. The percentages and numbers of thymic NKT cells at stage 0 (NK1.1-, $\left.\mathrm{CD} 44^{-}, \mathrm{CD} 24^{+}\right)$, stage $1\left(\mathrm{NK} 1.1^{-}, \mathrm{CD} 44^{-}, \mathrm{CD} 24^{-}\right)$, stage $2\left(\mathrm{NK} 1.1^{-}, \mathrm{CD} 44^{+}\right)$, and stage $3\left(\mathrm{NK} 1.1^{+}, \mathrm{CD} 44^{+}\right)$, based on flow cytometry analysis. Results are representative of three independent experiments. ( $n=5-6$ per group). c Thymic NKT cells were gated on PLZF, T-bet and ROR $\gamma t$ and the percentage and absolute numbers of NKT1, NKT2, and NKT17 were calculated ( $n=5-6$ per group). All data are presented as mean \pm S.E.M. ${ }^{\star} P<0.05$, ${ }^{\star \star} P<0.01$,

${ }^{\star \star \star} P<0.001$ with an unpaired two-tailed $T$-test

CD160 and BTLA are non-overlapping co-inhibitory receptors. Since BTLA, which is constitutively expressed on NKT cells, also exerts its inhibitory function through HVEM, we next examined whether $\mathrm{CD}_{160^{-}}{ }^{-}$mice show additional elevated cytokine secretion in the presence of BTLA/HVEM interaction. To test this, we injected blocking anti-BTLA mAbs (clone: pj196) into WT and $\mathrm{CD} 160^{-1-}$ mice prior to $a-\mathrm{GalCer}$ challenge in vivo (Fig. 5a). While the injection of anti-BTLA blocking mAbs in WT mice leads to a subtle increase in the level of IL- 4 and IFN- $\gamma$, BTLA blocking in CD160 $-1-$ mice caused additional increases in IL- 4 and IFN- $\gamma$ at $2 \mathrm{~h}$ and $15 \mathrm{~h}$ post $\alpha-$ GalCer injection, respectively. These data suggest that both CD160 and BTLA play a non- redundant co-inhibitory role in mice regulating liver inflammation during a-GalCer-induced acute hepatitis.

We next determined whether accelerated production of cytokines from CD160-I- NKT cells in the liver was associated with upregulation of co-stimulatory or downregulation of coinhibitory receptors on NKT cells ${ }^{25-31}$. When analyzed ex vivo, surface expression of CD154 (CD40L) was found to be significantly increased while that of BTLA was decreased on CD160-I- NKT cells upon $a-G a l C e r$ challenge. No obvious differences in PD-1, FasL, or CD69 expression were observed between WT and CD160-/- NKT cells (Fig. 5b). These data suggest that upregulation of a CD40L/CD40 co-stimulatory 
a
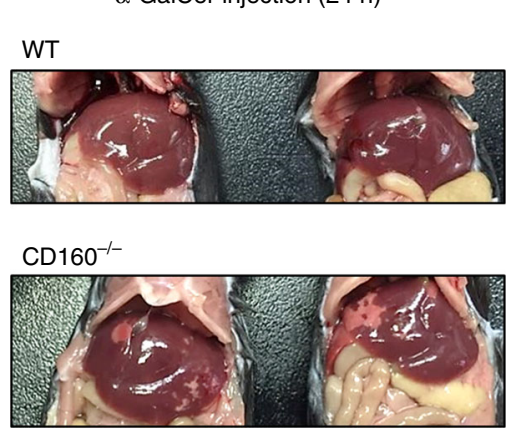

b
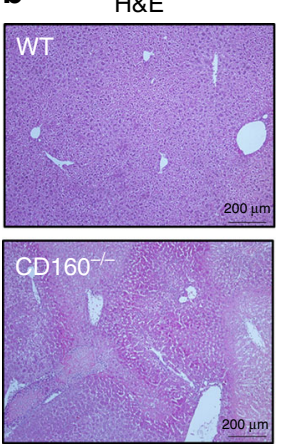
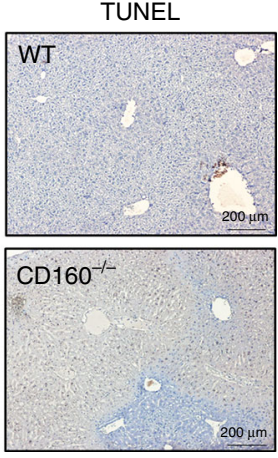
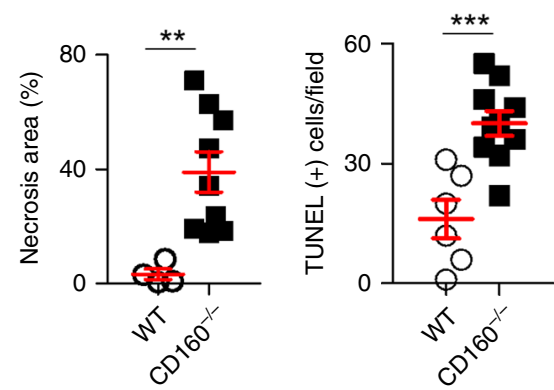

C

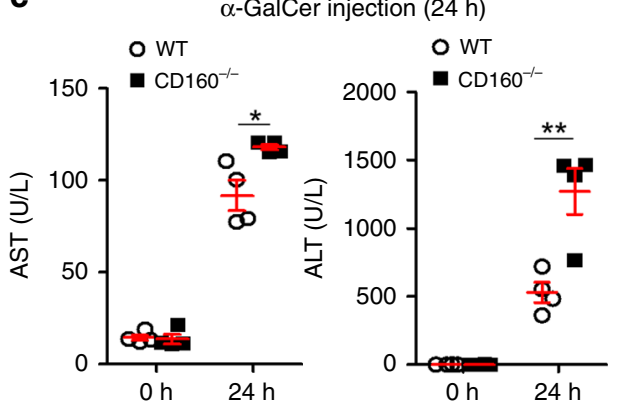

d

$\alpha$-GalCer injection

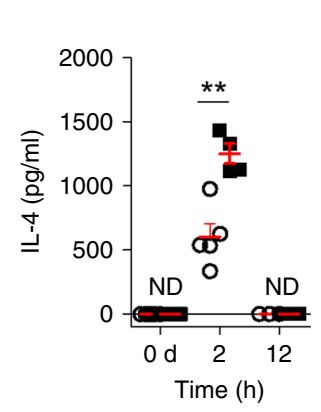

$2 \mathrm{~h}$

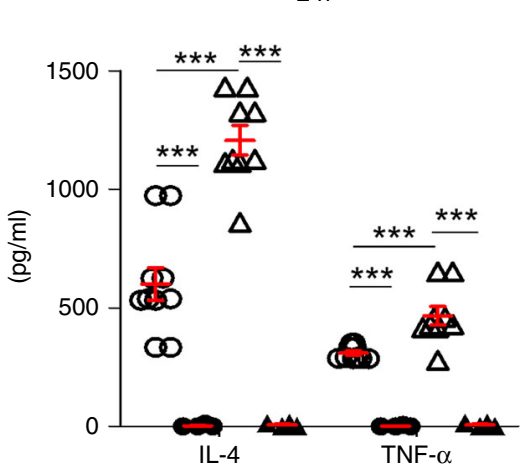

$\mathbf{f}$
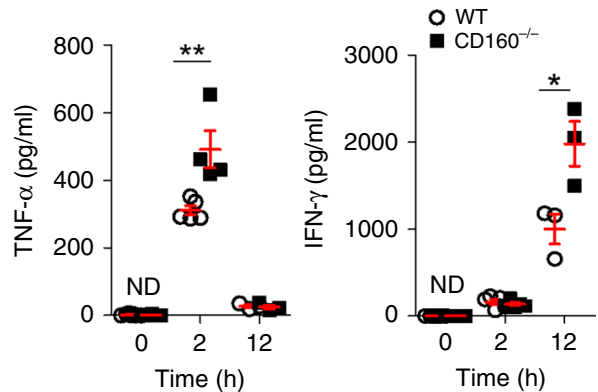

e

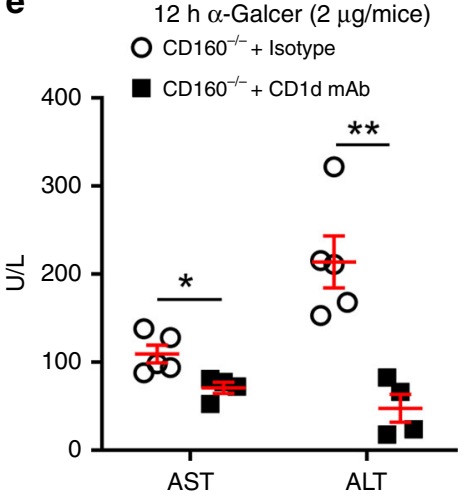

$12 \mathrm{~h}$

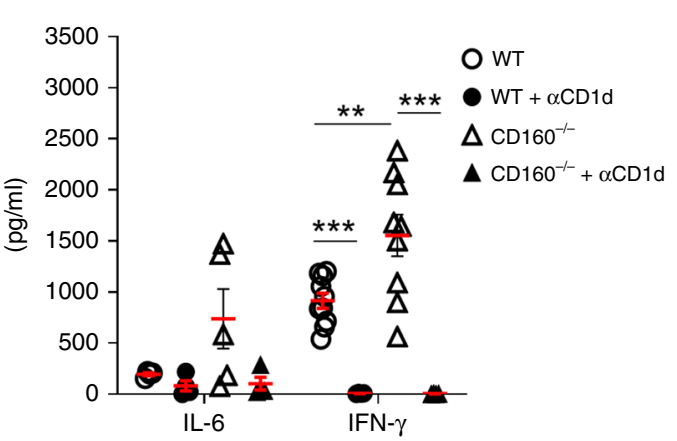

Fig. 3 CD160-/- mice are more susceptible to $\alpha$-GalCer-induced liver injury. a Representative images of livers of WT and CD160-/- mice $24 \mathrm{~h}$ following i. p. injection of $\alpha$-GalCer $(2 \mu \mathrm{g})$. $\mathbf{b}$ H\&E and TUNEL staining of liver sections in WT and CD160-/- mice. The percentage necrotic area ( $n=4-9$ per group) and TUNEL $(+)$ cells/field are shown as mean \pm S.E.M. (Random area, $n=6-10$ per group). Scale bars: $200 \mu$ m. c Serum transaminase activity (AST, ALT) 0 and $24 \mathrm{~h}$ following i.p. injection of $\alpha$-GalCer $(2 \mu \mathrm{g})$. Data are presented as mean \pm S.E.M. ( $n=4$ per group). d Serum was collected from WT and CD160-/- mice at different time points following $2 \mu \mathrm{g}$ of $\alpha$-GalCer injection and cytokines measured by CBA (ND, not detected). Results are representative of three independent experiments ( $n=3-8$ per group). e-f Mice were injected with anti-CD1d mAb (2OH2) $24 \mathrm{~h}$ before $\alpha-G a l C e r$ injection. e Analysis of serum transaminase activities (AST, ALT) $12 \mathrm{~h}$ following i.p. injection of $\alpha$-GalCer $(2 \mu \mathrm{g})$ with anti-CD1d or isotype control administration. Data are presented as mean \pm S.E.M. ( $n=4-5$ per group). $\mathbf{f}$ Analysis of serum levels of IL-4, TNF- $\alpha$, IL- 6 , and IFN- $\gamma$ in WT and CD160-/- mice at $2 \mathrm{~h}$ and $12 \mathrm{~h}$ after i.p. injection of $\alpha$-GalCer $(2 \mu \mathrm{g})$. The levels of various cytokines in serum were measured via CBA analysis $(n=4-10$ per group). All data are presented as mean \pm S.E.M. ${ }^{\star} P<0.05,{ }^{\star \star} P<0.01,{ }^{\star \star \star} P<0.001$ with an unpaired two-tailed $T$-test

pathway in NKT cells might have contributed to enhanced proinflammatory responses in the absence of CD160. Uncontrolled activation of NKT cells might have been influenced by defective DCs in CD160-I- mice. To assess whether the activation status of DCs was altered in the absence of CD160, we measured the levels of multiple ligands on DCs, including CD1d, CD40, CD80, CD95, PD-L1, and HVEM, during a-GalCer-induced hepatitis. As seen in Fig. 5c, no significant changes in surface expression were noted between WT and CD160 ${ }^{-I-}$ DCs. To further assess whether $\alpha$-GalCer-induced NKT cell activation was dependent on DCs, liver MNCs from WT and CD160-/- mice were co-cultured with $\mathrm{a}$-GalCer-pulsed DCs in vitro for $48 \mathrm{~h}$ and production of cytokines was measured by CBA analysis. As shown in Fig. 5d, CD160-/- liver MNCs produced high levels of IL-4, IFN- $\gamma$, and IL-17A regardless of whether WT or CD160-/- DCs were present (Fig. 5d). Therefore, aberrant activation of NKT cells, but not surrounding APCs, was primarily responsible for acute inflammation during $a$-GalCer-induced hepatitis in the absence of CD160.

Uncontrolled NKT activation was due to intrinsic defects. To investigate whether the phenotypic defects seen in $\mathrm{CD} 160^{-/-}$ mice upon a-GalCer challenge is intrinsic to NKT cells, we generated competitive mixed bone marrow chimera mice. For 
a

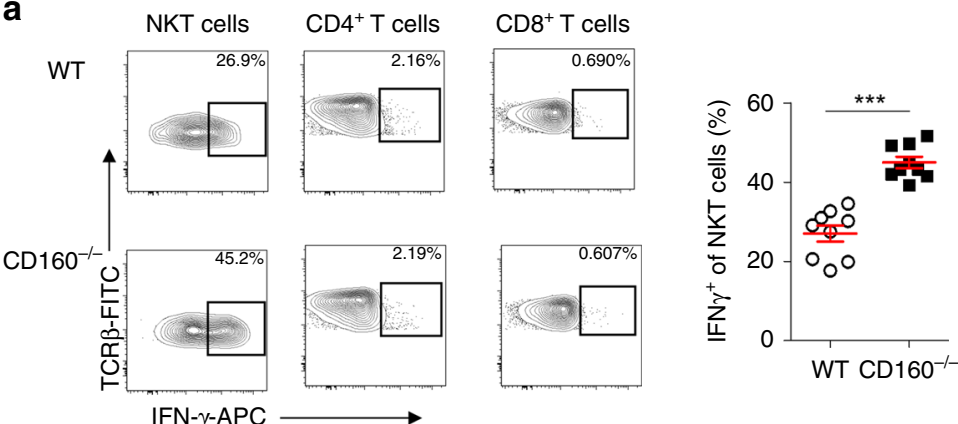

b
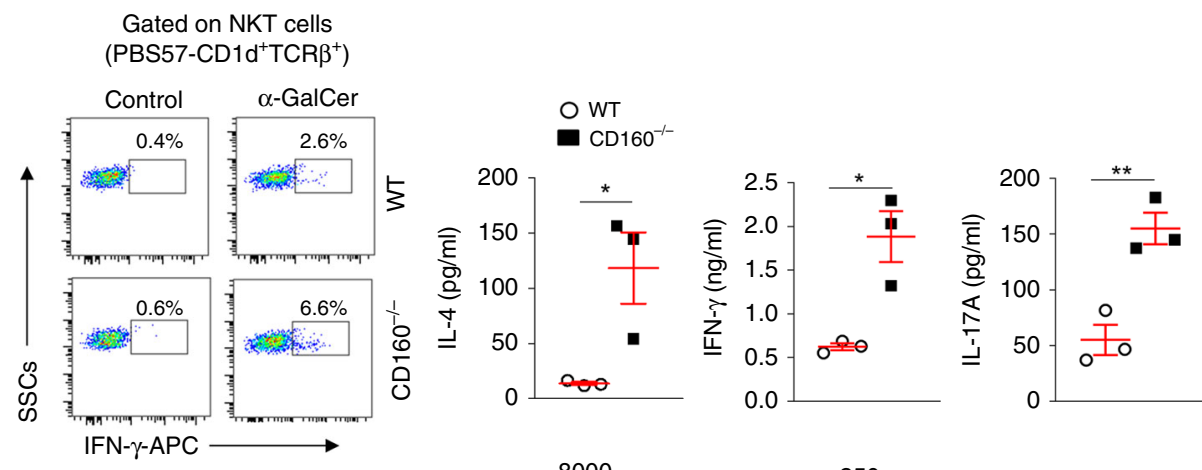

C
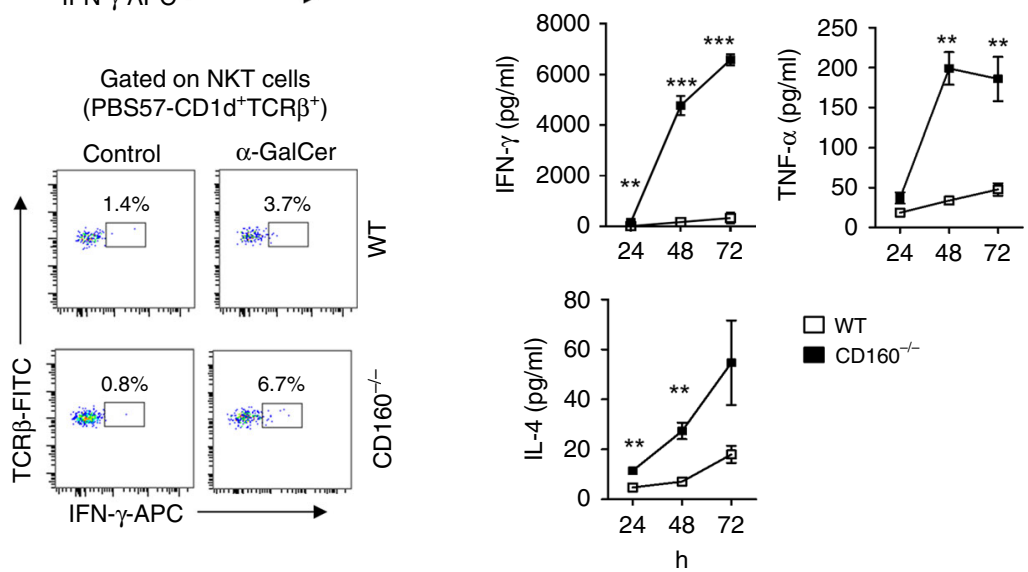

Fig. 4 Expression of IFN- $\gamma$ and surface co-receptors on NKT cells. a Representative flow cytometric analyses of intracellular IFN- $\gamma$ expression in liver NKT, $\mathrm{CD}^{+}$, and CD8 ${ }^{+}$T cells isolated from WT and CD160-/- mice injected with $2 \mu \mathrm{g}$ of $\alpha$-GalCer for $4 \mathrm{~h}$. Liver MNCs were treated with Brefeldin A to block cytokine release for the last $6 \mathrm{~h}$ in culture for intracellular IFN- $\gamma$ staining. The graphs represent the frequency of IFN- $\gamma$-expressing NKT cells $(n=9$ per each group). b Liver MNCs $\left(2 \times 10^{5}\right)$ from littermates of WT and CD160-/- mice were cultured with $\alpha$-GalCer $(100 \mathrm{ng} / \mathrm{ml})$ for $24 \mathrm{~h}$. Cells were treated with Brefeldin A to block cytokine release for the last $6 \mathrm{~h}$ in culture for intracellular IFN- $\gamma$ staining. Levels of IL-4, IFN- $\gamma$, and IL-17A in the culture supernatants at $24 \mathrm{~h}$ were measured by CBA. Results are representative of three independent experiments ( $n=3$ per group). c Splenocytes ( $3 \times 10^{5}$ cells) from littermates of WT and CD160-/- mice were cultured with $\alpha$-GalCer $(100 \mathrm{ng} / \mathrm{ml})$ and IL-2 $(50 \mathrm{U} / \mathrm{ml})$ for $24 \mathrm{~h}$. Cells were fixed and permeabilized prior to intracellular staining. Levels of IL-4, IL-6, IFN- $\gamma$, and TNF- $\alpha$ in the culture supernatants for 24,48 , and $72 \mathrm{~h}$ were measured by CBA ( $n=3$ per group). All data are presented as mean \pm S.E.M. ${ }^{\star} P<0.05,{ }^{\star \star} P<0.01,{ }^{\star \star \star} P<0.001$ with an unpaired two-tailed $T$-test

this, the bone marrow of $\mathrm{CD} 45.2^{+} \mathrm{CD} 160^{-1-}$ mice and "competitor" bone marrow from CD45.1 ${ }^{+}$WT mice were mixed at a 1:1 ratio and injected into $\gamma$-irradiated WT $\mathrm{C} 57 \mathrm{BL} / 6$ mice (Fig. 6a). The reconstituted mice were then sacrificed six to seven weeks post-injection and analyzed. The developing NKT cell compartment of the chimera mice was normal, as seen by the expression of CD44, NK1.1, and CD24 on thymocytes (Fig. 6b, c). Upon $\alpha$-GalCer injection of mixed chimeric mice, secretion of IFN- $\gamma$ was greatly enhanced in CD45.2 $2^{+} \mathrm{CD} 160^{-1-}$ NKT cells compared with CD45.1 ${ }^{+}$WT NKT cells (Fig. 6d). These data indicate that the cytokine defects are intrinsic to NKT cells, and not due to extrinsic defects.
$\mathrm{CD}_{160}{ }^{-/-}$mice suffer from Concanavalin A-induced hepatitis. We next investigated whether CD160 contributes to NKT cell activation in more physiologic settings of acute hepatitis. Although $a$-GalCer presented by CD1d provides specific NKTdependent activation both in vivo and in vitro, Con A-induced murine hepatitis is a well-documented experimental model for human autoimmune acute hepatitis or viral hepatitis ${ }^{32,33}$. To define the role of CD160 on NKT cells in an autoimmune hepatitis model, we first measured surface CD160 expression on NKT cells after Con A $(15 \mathrm{mg} / \mathrm{kg})$ administration in vivo. Similar to $a$-GalCer stimulation, Con A administration resulted in elevation of surface CD160, up to 3-fold, on PBS57-CD1d ${ }^{+}$TCR $\beta^{+}$ 
a
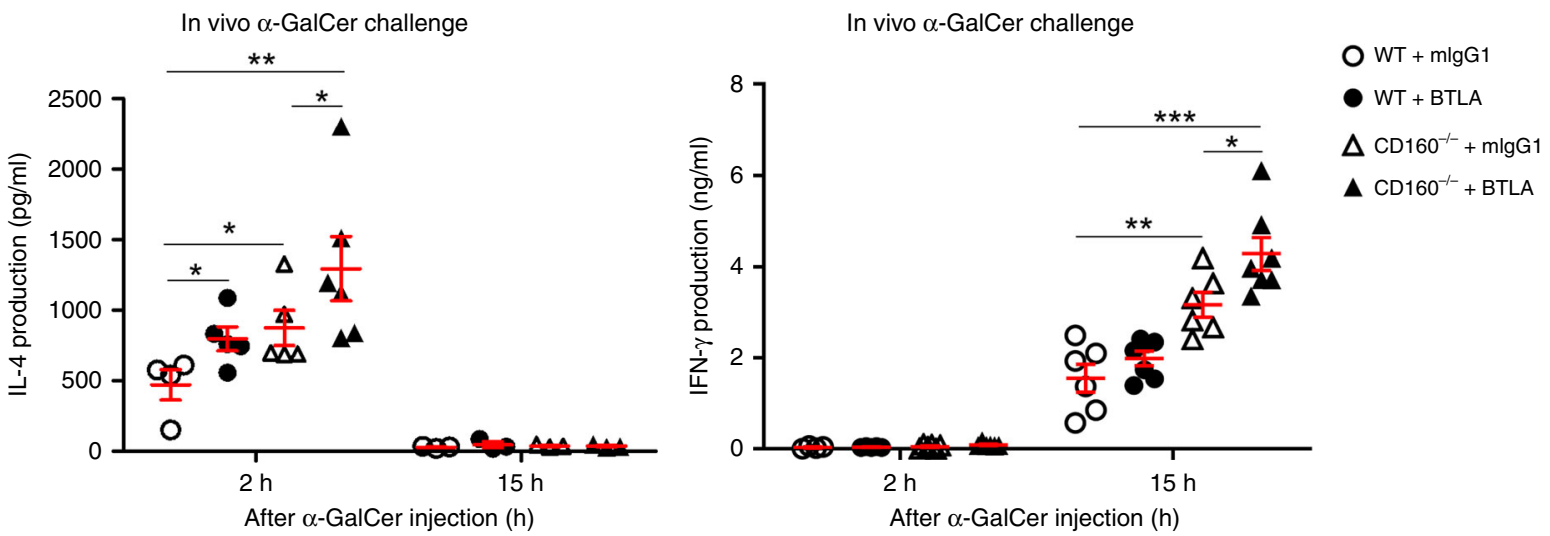

b

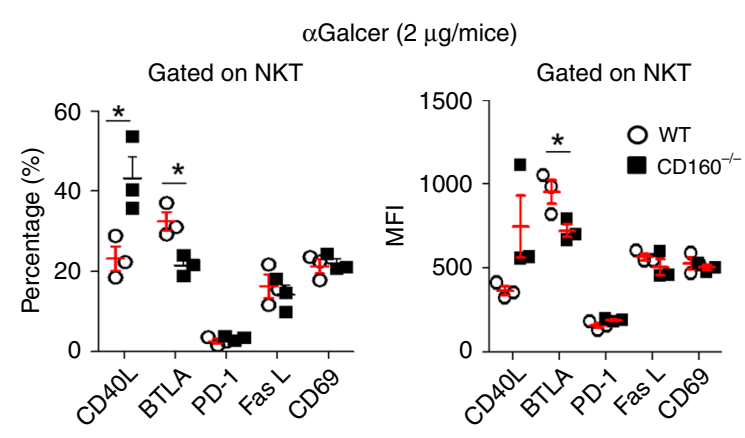

C

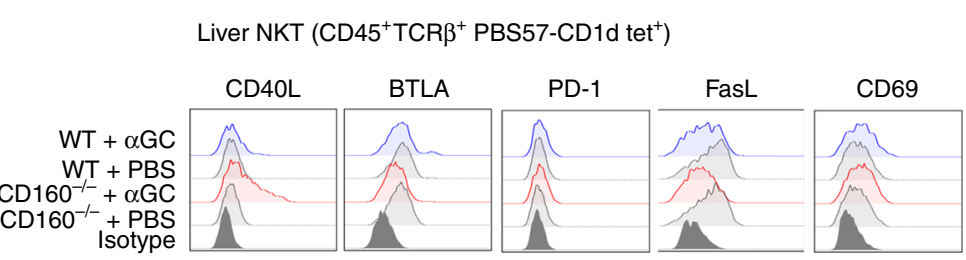
Liver DC (CD45+ CD11C $\left.{ }^{+} \mathrm{MHCII}\right)$
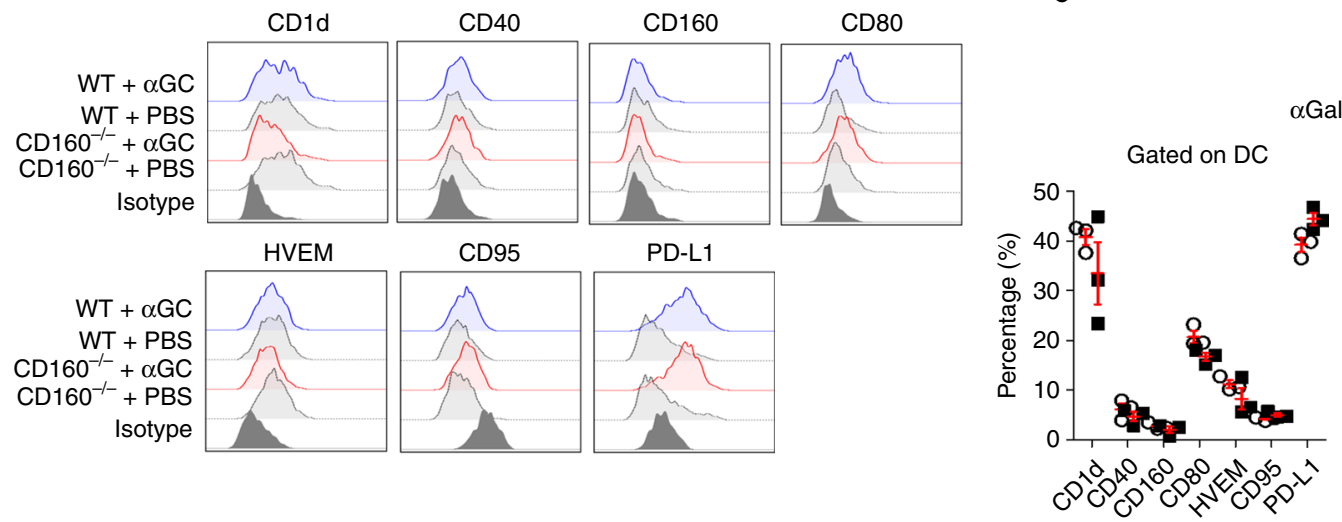

$\alpha$ Galcer $(2 \mu \mathrm{g} /$ mice $)$

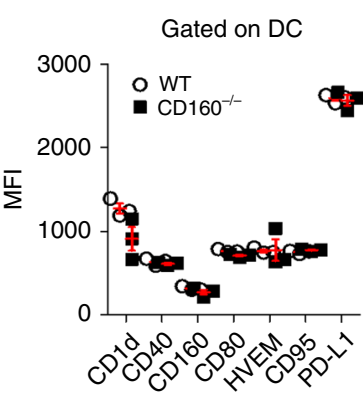

d
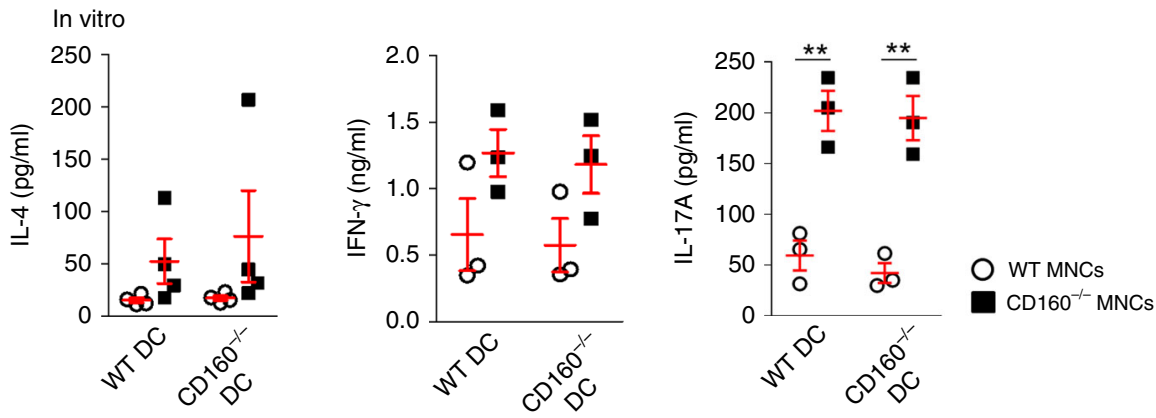

Fig. $5 \alpha$-GalCer challenge in the presence of BTLA blocking mAbs in CD160-/- mice. a mlgG1 or anti-BTLA mAbs were injected into WT or CD160-/mice $2 \mathrm{~h}$ prior to $\alpha$-GalCer in vivo challenge and serum levels of IL-4 and IFN- $\gamma$ were measured by CBA 2 and $15 \mathrm{~h}$ post $\alpha-\mathrm{GalCer}$ challenge $(n=3-7$ per group). Surface expression of co-stimulatory and co-inhibitory receptors on NKT (b) and dendritic cells (c) from WT and CD160-/- mice $4 \mathrm{~h}$ before and after $2 \mu \mathrm{g}$ of $\alpha-\mathrm{GalCer}$ challenge in vivo. Left: Representative FACs plots from three independent experiments. Right: Average percentages or MFIs were plotted for each receptor as bar graphs ( $n=3-5$ per each group). d Co-cultures of WT or CD160-/- liver MNCs with WT or CD160-/- BMDCs for 48 h in vitro. BMDCs were pulsed with $\alpha$-GalCer for $16 \mathrm{~h}$ prior to co-culture $\left(n=3-4\right.$ per group). All data are presented as mean \pm S.E.M. ${ }^{\star} P<0.05,{ }^{\star \star} P<0.01$, ${ }^{\star \star \star} P<0.001$ with an unpaired two-tailed $T$-test 
a

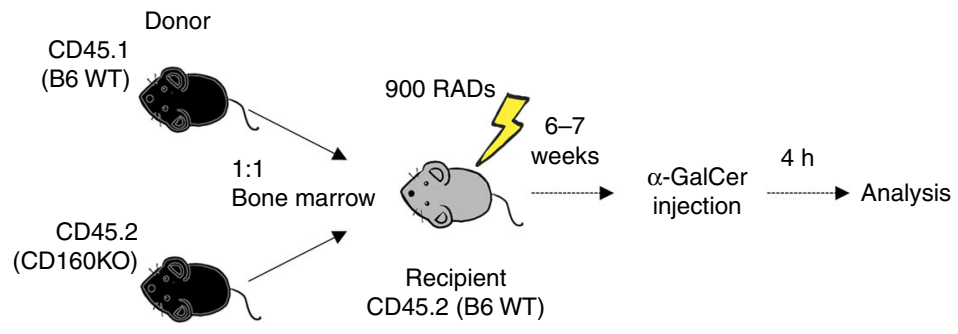

b

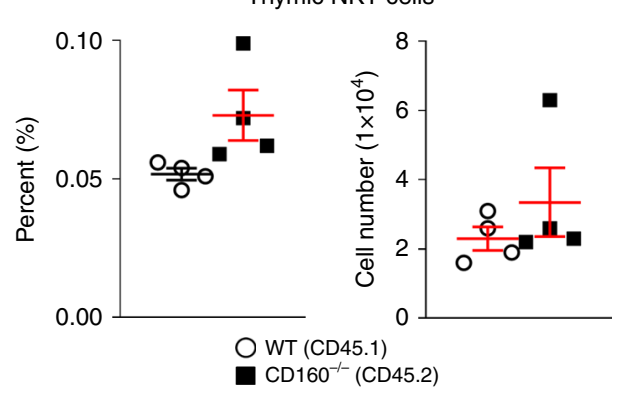

d

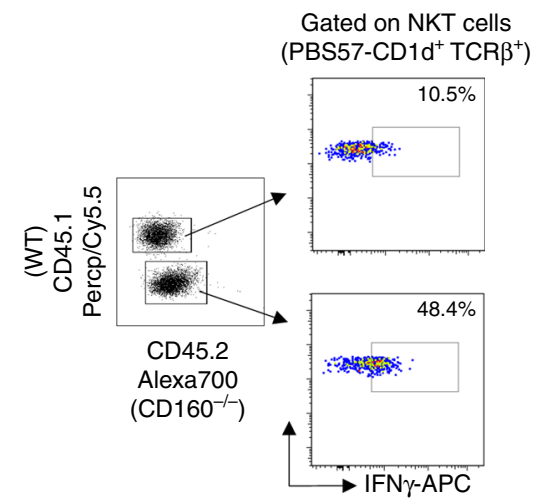

OWT (CD45.1)

C
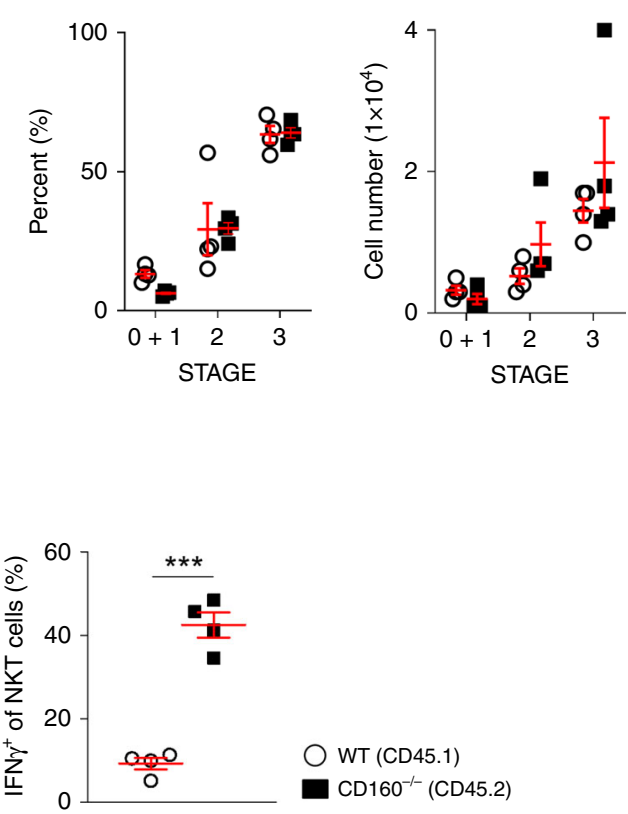

Fig. 6 CD160-/- NKT cells show intrinsic defects during acute hepatitis. a Mixed bone marrow (BM) chimera mice were generated using a 1:1 ratio of WT (CD45.1) and CD160-/-(CD45.2) BM cells for transfer into WT hosts; 6-7 weeks later, mice were injected with $2 \mu \mathrm{g}$ of $\alpha$-GalCer for 4 h. b-c Thymic NKT cells were analyzed by multiparametric flow cytometry using TCR $\beta$, CD1d-tetramer, CD44, NK1.1, CD45.1, and CD45.2 to identify NKT cells in mixed BM chimera mice ( $n=4$ per each group). d Representative FACS plots of IFN- $\gamma$ in NKT cells following in vivo challenge with $2 \mu$ of $\alpha$-GalCer. All data represent the mean \pm S.E.M. Results are representative of two independent experiments $\left(n=4\right.$ per group). ${ }^{\star} P<0.05,{ }^{\star \star} P<0.01,{ }^{\star \star \star} P<0.001$ with a paired T-test

NKT cells isolated from the liver and spleen in WT mice (Fig. 7a). To further investigate the role of CD160 receptor in an autoimmune hepatitis model, we injected a lethal dose $(30 \mathrm{mg} / \mathrm{kg})$ of Con A i.v. into WT and $\mathrm{CD} 160^{-1-}$ mice with and followed their survival over time. As seen in Fig. 7b, upon Con A challenge, over $75 \%$ of $\mathrm{CD} 160^{-/-}$mice died within $24 \mathrm{~h}$ while the majority of WT mice survived (Fig. 7b). As seen in the $a-G a l C e r$ challenge, $\mathrm{CD} 160^{-1-}$ mice demonstrated aggravated tissue damage during Con A-induced hepatitis compared with WT mice, along with elevated AST and ALT in serum (Figs 7c, d). In addition, IL-4, IFN- $\gamma$, and TNF- $\alpha$ levels in CD160-/- mice were significantly higher than in WT mice (Fig. 7e). The mRNA transcripts of $I L-4$, $I F N-\gamma$, and TNF- $\alpha$ were also significantly higher after Con A injection in $\mathrm{CD}_{160^{-/-}}$mice than WT, indicating that $\mathrm{CD} 160$ negatively regulates cytokine expression in NKT cells (Fig. 7f).

To show that this defect was coming from NKT cells, but not $\mathrm{CD} 8^{+} \mathrm{T}$ cells, we performed in vivo depletion of $\mathrm{CD} 8^{+} \mathrm{T}$ cells by injecting anti-CD8 mAbs $24 \mathrm{~h}$ before Con A injection. Regardless of $\mathrm{CD}^{+} \mathrm{T}$ cell depletion, $\mathrm{CD} 160^{-/-}$mice showed a decreased rate of survival compared with WT mice (Supplementary Fig. 6).
When we analyzed the activation status of hepatic NKT cells upon Con A stimulation, the early activation marker CD69 was increased significantly in the NKT cells of $\mathrm{CD} 60^{-/-}$mice (Fig. 7g). Upon Con A treatment, CD95 ligand expression on hepatic NKT cells was upregulated and hepatic injury was induced by CD95-CD95 ligand (L) cytotoxicity ${ }^{34}$. We found that CD160 ${ }^{-1-}$ mice had higher CD95L on hepatic NKT cells than WT mice (Fig. 7g). Our results indicate that loss of CD160 leads to hyperactivation of NKT cells and liver inflammation via upregulation of CD95L. These results provide strong evidence that $\mathrm{CD} 160$ plays a critical role as a negative regulator in the activation of NKT cells.

\section{Discussion}

Co-inhibition of antigen-induced signals is critical for the contraction of adaptive immune responses as well as for managing uncontrolled immune responses. Here, we report that CD160 serves as an important co-inhibitory receptor of NKT cells during early innate immune responses, preventing aberrant 
a

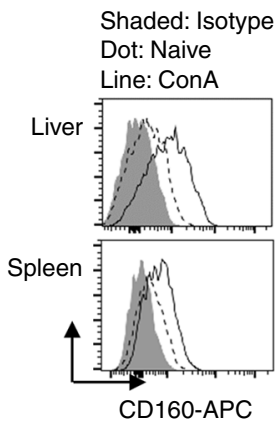

C
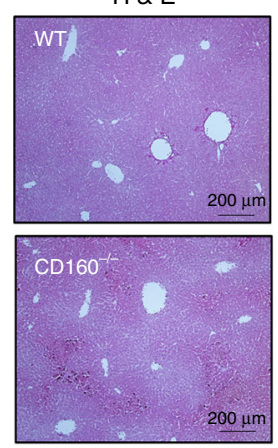

e

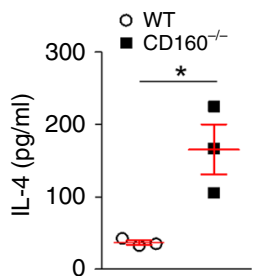

Gated NKT cells (PBS57-CD1d ${ }^{+}$TCR $\beta^{+}$)

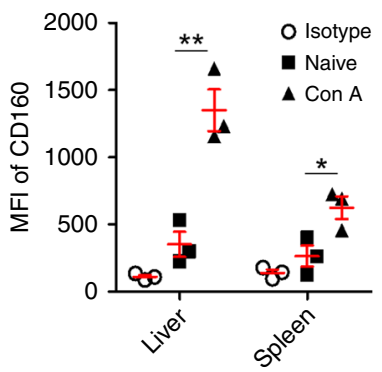

b

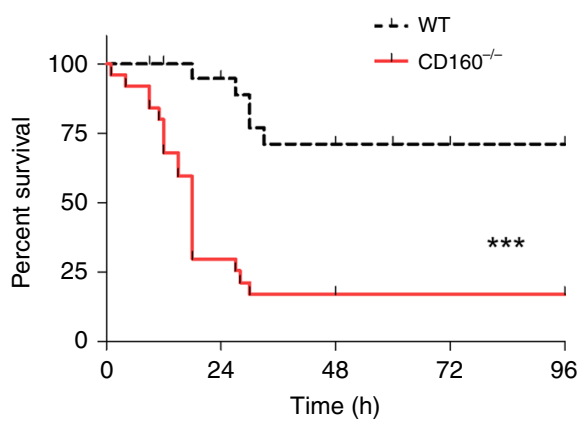

d

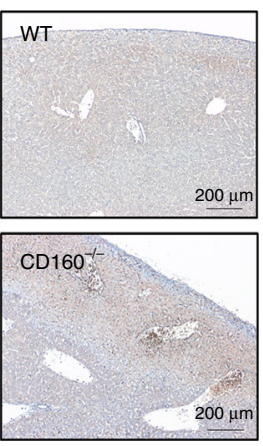

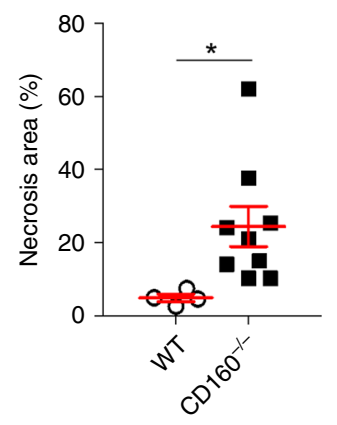

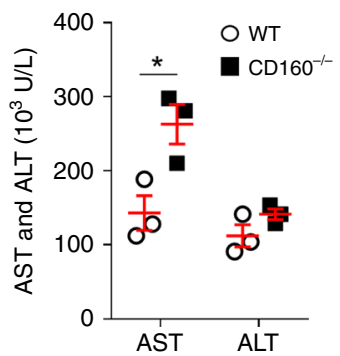

g

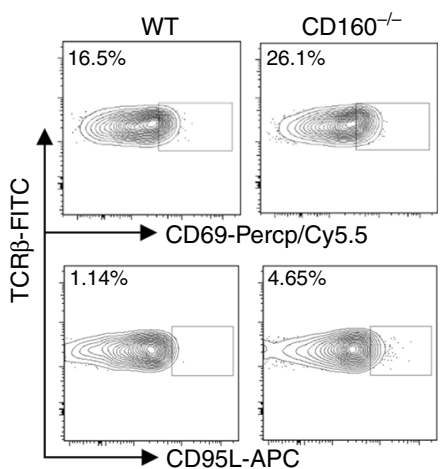

f $\quad \mathrm{ODT}_{\mathrm{CD} 160^{-1-}}$
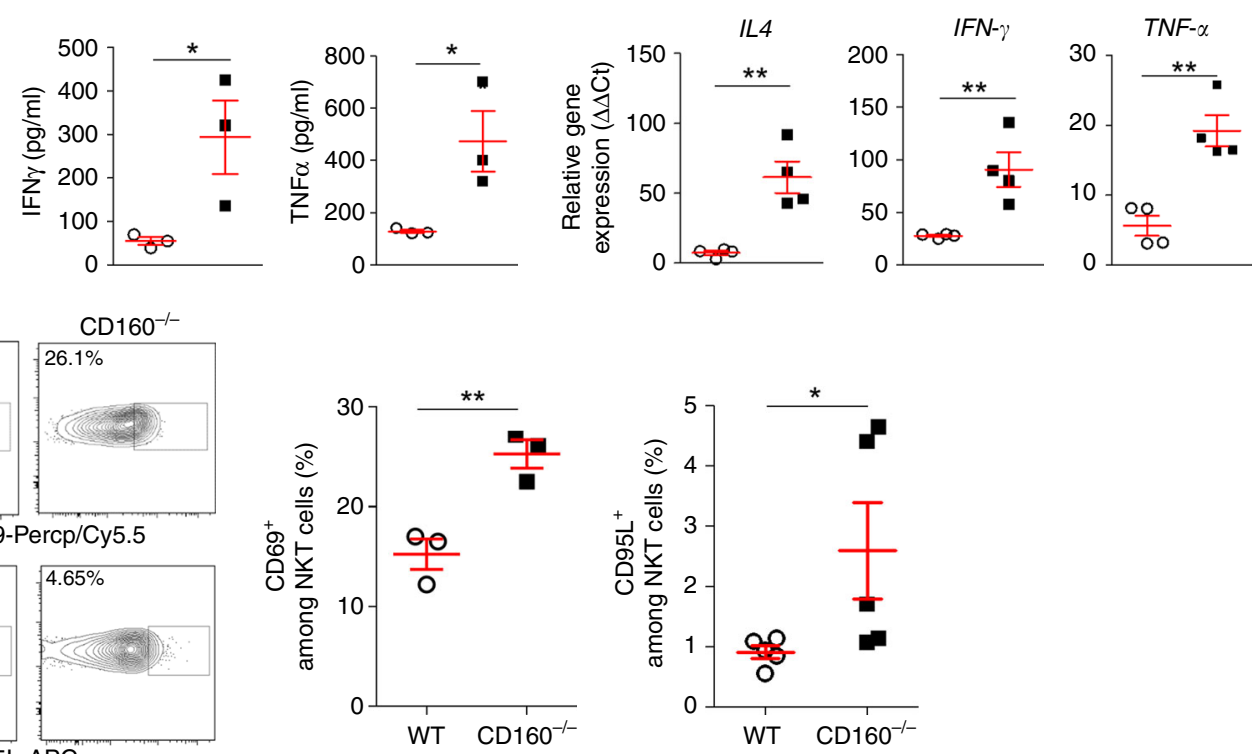

Fig. 7 Susceptibility to Con A-induced hepatitis in CD160-/- mice. a Representative histograms showing CD160 expression in gated PBS57-CD1d tetramer ${ }^{+}$ TCR $\beta^{+}$NKT cells from the liver and spleen $4 \mathrm{~h}$ before and after i.v. injection with Con A $(15 \mathrm{mg} / \mathrm{kg})$. The graph represents average mean fluorescence intensities (MFI) of CD160 expression of NKT cells from liver and spleen ( $n=3$ per group). b WT and CD160 ${ }^{-/-}$mice were intravenously injected with Con A $\left(30 \mathrm{mg} / \mathrm{kg}\right.$ ), and the rate of survival was recorded $\left(n=21-25\right.$ per group). ${ }^{\star} P<0.05,{ }^{\star \star} P<0.01$, ${ }^{\star \star \star} p<0.001$ with a Log-rank (Mantel-Cox) Test. c The percentage of necrotic area and TUNEL ( + ) cells/field are shown as mean \pm S.E.M. ( $n=4-9$ per group). Scale bars: $200 \mu \mathrm{m}$. d WT and CD160 $/-$ mice were intravenously injected with Con A (15 mg/ $\mathrm{kg}$ ), and serum was obtained to measure AST and ALT levels at $2 \mathrm{~h}$ ( $n=3$ per group). e Analysis of serum levels of IL-4, IFN- $\gamma$, and TNF- $\alpha$ in WT and CD160-/- mice $4 \mathrm{~h}$ after intravenous injection of Con A (15 mg/kg) by CBA and data presented as the mean \pm S.E.M. ( $n=3$ per group). f Quantitative RT-PCR analysis for IL-4, IFN- $\gamma$, and TNF- $\alpha$ mRNA levels in the livers of WT and CD160-/- mice $4 \mathrm{~h}$ after intravenous injection of Con A ( $15 \mathrm{mg} / \mathrm{kg}$ ). Gene expression was normalized to HPRT mRNA levels in each sample ( $n=4$ per group). $\mathbf{g}$ Representative flow cytometry analysis showing expression of CD69 and CD95 Ligand in NKT cells from WT and CD160-/- mice $4 \mathrm{~h}$ after Con A treatment (15 mg/kg). Graphs represent the percentage of the CD69 and CD95L positive portions in NKT cells among liver MNCs from WT and CD160-/- mice $(n=3-5$ per group). All data are representative of three different experiments and presented as mean \pm S.E.M. ${ }^{\star} P<0.05,{ }^{\star \star} P<0.01$ with an unpaired two-tailed $T$-test or Mann-Whitney test 
activation and subsequent tissue damage. While the absence of CD160 did not affect the normal development and differentiation processes of NKT cells in CD160-/- mice, it shifted the balance of NKT cells toward more uncontrolled hyperactivation in the periphery and secondary lymphoid organs. In both a-GalCerand Con A-induced murine hepatitis models, CD160 ${ }^{-/-}$mice suffered from severe inflammation with elevated IL-4, IL-6, IFN$\gamma$, and TNF- $\alpha$ and could not fully recover from lethal Con A challenge. The inhibitory role of CD160 in NKT cells appears to be independent from BTLA, as simultaneous blocking of BTLA using specific anti-BTLA mAbs further elevated NKT-dependent cytokine production. These data show that both CD160 and BTLA serve as non-overlapping negative regulators of NKT cells during the early innate immune response.

The negative regulatory role of CD160 in NKT cells seen here is somewhat contradictory to its known co-stimulatory function in NK cells and $\mathrm{CD}^{+} \mathrm{T}$ cells ${ }^{12,35,36}$. However, it coincides with findings in $\mathrm{CD}^{+} \mathrm{T}$ cells, which have shown that in vitro crosslinking of $\mathrm{CD} 60^{37}$ or its engagement by HVEM on APCs coinhibited $\mathrm{T}$ cell activation ${ }^{5,38-40}$. Since NKT cells constitutively express BTLA as a strong inhibitory receptor transmitting signals from HVEM $^{26,41}$, having CD160 as an additional negative receptor binding to HVEM appears quite redundant. However, one can speculate that NKT cells may utilize BTLA to bind HVEM during the initial phase of immune response, and then allow CD160 upregulation to strengthen binding to HVEM in the later phase. Although this hypothesis awaits experimental confirmation, our results shown here support the fact that CD160 acts as a critical co-inhibitory receptor in NKT cells, which is separate from the role of BTLA.

Since NKT cells rarely express HVEM on their surface (Fig. 1c), both antigenic signals and HVEM signals would have been delivered in trans from neighboring APCs, including DCs and Kupffer cells. HVEM also binds LIGHT, and HVEM/LIGHT interactions have been shown to co-stimulate T cell activation ${ }^{42}$. Engagement of HVEM on T cells by LIGHT expressed on DC costimulates $\mathrm{CD}^{+} \mathrm{T}$ cells and also induces proliferation and differentiation of $\mathrm{CD}^{+} \mathrm{T}$ cells. The HVEM/BTLA pathway, however, can downmodulate TCR-mediated signaling similarly in both T cell subsets. However, we found that NKT cells do not express a significant level of LIGHT on their surface. Therefore, the HVEM/LIGHT/ BTLA/CD160 signaling axis is expected to present both positive and negative signaling in NKT cells, depending on which receptor/ligand is operated in the context of neighboring interactions. Consequently, $\mathrm{HVEM}^{-1-}$ mice exhibit attenuated Con A-induced hepatitis, low serum AST and ALT, and reduced serum IFN- $\gamma^{43}$. In these mice, $\alpha$-GalCer-stimulated NKT cells in liver MNCs did not show any differences in surface co-stimulatory or co-inhibitory receptors; however, they did produce higher IL-17 and IL-22 without affecting IFN- $\gamma$ and TNF- $\alpha$, promoting tissue repair. Since NKT cells initiate acute hepatitis pathology in Con A-challenged mice, the attenuated phenotype in $\mathrm{HVEM}^{-1-}$ mice could be associated with other HVEM-expressing liver MNCs, such as $\mathrm{CD}^{+} \mathrm{T}$ cells, in these mice. In this context, accelerated NKT cell activation in CD160 ${ }^{-1-}$ mice could be due to increased availability of HVEM on $\mathrm{CD}^{+} \mathrm{T}$ cells, which could, in turn, lead to severe inflammation and acute hepatic failure.

Our data based on $\mathrm{CD}_{160^{-/}}$and mixed bone marrow chimera models highlight that CD160 serves as a co-inhibitory rather than a co-stimulatory receptor on NKT cells. Both WT DC and $\mathrm{CD} 160^{-1-}$ DC express comparable levels of surface co-stimulatory/co-inhibitory ligands, and exert similar accelerated cytokine production in CD160-/- NKT cells compared with WT NKT cells, confirming the mixed bone marrow chimera results suggesting that the defect is intrinsic to NKT cells, not DCs or surrounding APCs.

Currently, the precise mechanism underlying CD160-mediated negative signals in NKT cells remains unclear. However, CD160 likely either takes over BTLA binding from HVEM $^{4,44}$ or potentiates CD160/BTLA/HVEM binding, thereby dominating co-inhibition of NKT signaling during a slightly later phase of innate immune reactions. Interestingly, CD160-/- NKT cells downregulated surface BTLA during acute hepatitis (Fig. 5b). These data suggest that CD160 may be required for BTLA expression in NKT cells to deliver co-inhibitory signals in normal innate immune responses. Hyperactivation of NKT cells in the absence of CD160 may also be associated with upregulation of CD40L, shifting the balance toward CD40/CD40L-costimulation over HVEM/BTLA co-inhibition (Fig. 5b). In human CD4 ${ }^{+}$ $\mathrm{T}$ cells, cross-linking of CD160 in the presence of anti-CD3- and anti-CD28-mAb-coated beads suppressed the expression of $I L 2$, IL6, and IL17A as well as IL2RA (CD25) mRNA transcripts without affecting known suppressive genes, TGFB1, IL10, PDCD1, CD274, PDCD1LG2 and CTLA $4^{37}$. On preliminary RNAseq analysis, the level of $I L-10$ (-4.7-fold) and CTLA4 (-3.3-fold) was significantly reduced in $\mathrm{CD}_{160}{ }^{-/}$upon $\alpha$ GalCer challenge. Since the role of CD160 in NKT cells mimic that in $\mathrm{CD} 4^{+} \mathrm{T}$ cells, similar gene expression changes can be expected in NKT cells and contribute to the co-inhibitory phenotypes of NKT cells (Park et al., unpublished data).

In summary, we have shown that CD160 is an important coinhibitory receptor in NKT cells during acute innate immune responses. Although its ligand HVEM functions as a bidirectional switch in T cells, whereby the outcome depends on the receptors engaged, the functional consequence of CD160/BTLA/HVEM interactions in NKT cells is co-inhibitory, with deficiency aggravating NKT-mediated acute hepatitis. Therefore, both CD160 and BTLA are required for normal NKT-mediated innate immune responses. Taken together, our findings of CD160 as an additional co-inhibitory receptor in NKT cells shed light on the development of CD160/BTLA/HVEM pathways as potential therapeutic targets for the treatment of acute liver inflammatory diseases.

\section{Methods}

Mice. Wild type (WT) C57BL/6 mice were purchased from Orient Bio (Orient Bio. Inc., Seongnam, Korea). CD160 ${ }^{-1-}$ mice on a C57BL/6 background were kindly provided by Prof. Yang-Xin Fu (UT Southwestern Medical Center, TX, USA). Mice between 8 and 12 weeks of age were used for experiments. All animal experiments were approved by the Institutional Animal Care and Use Committee of Korea University (approval number: KUIACUC-20160518-1) and followed the guidelines and regulations of the Institutional Animal Care and Use Committees of Korea University.

Cell preparation. The liver was removed from mice after perfusion with DPBS via the hepatic portal vein. Perfused liver homogenates were incubated with collagenase IV (Worthington, NJ, USA) for $15-30 \mathrm{~min}$ at $37^{\circ} \mathrm{C}$, and were passed through a $100-\mu \mathrm{m}$ strainer. Cells were centrifuged at $800 \times$ for $5 \mathrm{~min}$ and pellets were suspended in $33 \%$ Percoll (GE Healthcare Bio-Sciences, PA, USA). The suspension was centrifuged at $800 \times g$ for $30 \mathrm{~min}$ and RBCs were removed with ACK lysis buffer (Gibco, MA, USA). Lymphocytes from spleens of WT and $\mathrm{CD}_{160^{-1-}}$ mice were homogenized using a $70-\mu \mathrm{m}$ strainer (SPL, Korea) to isolate single cells.

Analysis of cell activation in vitro. BMDCs were cultured with $10 \mathrm{ng} / \mathrm{ml}$ GMCSF (BioLegend, CA, USA) in RPMI1640 with 5\% FBS, $100 \mathrm{U} / \mathrm{ml}$ penicillin/streptomycin, $0.1 \%$ non-essential amino acids, $10 \mathrm{mM}$ HEPES, and $55 \mu \mathrm{M} 2$ mercaptoethanol. BMDCs were stimulated with $\alpha$-GalCer $(100 \mathrm{ng} / \mathrm{ml})$ for $16 \mathrm{~h}$ and cultured for $48 \mathrm{~h}$ with liver MNCs in round-bottom 96-well plates ${ }^{45}$. To measure cytokine production, culture supernatants were analyzed for various cytokine levels using a CBA kit (BD Bioscience) and ELISA Kit (BioLegend). For intracellular staining, liver MNCs were stimulated for $24 \mathrm{~h}$ with $\alpha$-GalCer $(100 \mathrm{ng} / \mathrm{ml})$ in the presence of Brefeldin A (BioLegend) or Golgistop (BD Pharmingen, CA, USA). 
Flow cytometry. Fluorochrome-conjugated antibodies against mouse $\mathrm{CD} 3 e$ (clone: 145-2C11, [eB], cat.: \#11-0031-85, dilution: 1:300), CD4 (RM4-5, [BL], \#100540, 1:800), TCR- $\beta$ (H57-597, [eB], \#11-5961-82, 1:400), NK1.1 (PK136, [eB], \#125941-83, 1:200; PK136, [eB], \#25-5941-81, 1:200), CD160 (ebioCNX46-3, [eB], \#12-1601-82, 1:400), CD69 (F23.1, [eB], \#11-0691-85, 1:300), CD8a (53-6.7, [eB], \#11-0081-82, 1:300), CD19 (1D3, [BD], \#551001, 1:500), CD44 (IM7, [BD], \#560570, 1:400), CD24 (M1/69, [BL], \#101814, 1:1,000), CD28 (37.51, [eB], \#250281-81, 1:500), CD45 (30-F11, [BL], \#103116, 1:800), IL-4 (11B11, [BL], \#504117, 1:400), IFN- $\gamma$ (XMG-1, [BD], \#554413, 1:400), BTLA (6F7, [eB], \#17-5956-82, 1:400), HVEM (LH1, [eB], \#17-5962-82, 1:400), CD178 (MFL3, [eB], \#17-5911-82, 1:500), CD80 (16-10A1, [eB], \#11-0801-82, 1:400), CD40 (3/23, [BL], \#124607, 1:500), CD137 (1AH2, [BD], \#558975, 1:200), CD134 (OX-86, [eB], \#12-1341-81, 1:400), CD1d (1B1, [BL], \#123507, 1:200), CTLA-4 (UC10-4B9, [eB], \#12-1522-81, 1:500), PD-1 (J43, [eB], \#11-9985-85, 1:300), PD-L1 (10 F.9G2, [BL], \#124312, 1:500), CD154 (MR1, [BL], \#106510, 1:500), CD95 (clone: 15A7, [eB], \#46-095180, 1:500), PLZF (9E12, [BL], \#145808, 1:500), T-bet (4B10, [eB], \#25-5825-80, 1:500), ROR $\gamma \mathrm{t}$ (B2D, [eB], \#17-6981-80, 1:500), CD45.1 (A20, [eB], \#45-0453-82, 1:500), CD45.2 (104, [BL], \#109822, 1:500), F4/80 (BM8, [eB], \#11-4801-82, 1:200), CD11b (M1/70, [eB], \#56-0112-82, 1:500), CD11C (N418, [BL], \#117310, 1:500), MHCII (M5/114.15.2, [BL], \#107630, 1:800), Ly6G (1A8, [BL], \#127618, 1:800), and Ly6C (HK1.4, [BL], \#128006, 1:500) were purchased from eBioscience [eB], $\mathrm{BD}$ Pharmingen $[\mathrm{BD}]$, or BioLegend [BL]. PE-labeled CD1d tetramer loaded with $\alpha$-GalCer was obtained from the NIH tetramer facility. Fixable viability stain 700 (BD Bioscience, CA, USA) or 7AAD (BD Bioscience) was used for dead cell exclusion. Intracellular staining was performed using the Cytofix/Cytoperm kit according to the manufacturer's protocol. Flow cytometric analysis was performed with FACS Canto II (BD Bioscience) and data were analyzed with FlowJo software (ThreeStar, OR, USA). For measurement of cytokine levels, peripheral blood was collected in vacutainers via retro-orbital bleeding. Levels of cytokines in serum and supernatants were measured with the Mouse Th1/Th2/Th17 Cytokine Kit (BD Biosciences) according to the manufacturer's instructions. Data were analyzed with the FCAP Array software (Soft Flow, version 3.0).

Acute hepatitis model. Mice were i.v. or i.p. injected with vehicle or $2 \mu \mathrm{g} \alpha$-GalCer (Funakoshi, CA, USA) in $200 \mu \mathrm{l}$. Con A (Sigma-Aldrich, MO, USA) was dissolved in PBS and intravenously (i.v.) injected into mice at a sub-lethal concentration $(15 \mathrm{mg} / \mathrm{kg}$ ). For survival studies, a $30 \mathrm{mg} / \mathrm{kg}$ lethal dose was applied. For depletion of $\mathrm{CD} 8^{+} \mathrm{T}$ cells, mice were intraperitoneally injected with anti-CD8 mAb (clone: YTS 169.4) $24 \mathrm{~h}$ before Con A injection. For blocking of BTLA, mice were intravenously injected with anti-BTLA (clone: pj196, BioXcell, NH, USA) $2 \mathrm{~h}$ before $\mathrm{a}$ GalCer $(2 \mu \mathrm{g})$ injection. For neutralizing of CD1d, mice were intraperitoneally administrated $200 \mu \mathrm{g}$ of anti-CD1d antibodies (clone: 20H2, BioXcell) on day 1 before $\alpha$-GalCer $(2 \mu \mathrm{g})$ injection.

Generation of mixed bone marrow chimeras. Chimeric mice were generated by whole-body $\gamma$-irradiation followed by transfer of bone marrow cells. Briefly, CD45.2 WT mice were irradiated with a dose of $9 \mathrm{~Gy}$ and then injected i.v. with $1 \times 10^{6}$ mixed bone marrow cells (ratio 1:1) from the femurs and tibias of CD45.1 WT and CD45.2 CD160 ${ }^{-1-} 6 \mathrm{~h}$ later. Mice were administered antibiotics (neomycin $1.1 \mathrm{mg} / \mathrm{ml}$ and polymyxin B sulfate $1000 \mathrm{U} / \mathrm{ml}$ in acidic drinking water) for 2 weeks. After 6 weeks, mice were injected i.p. with $\alpha$-GalCer $(2 \mu \mathrm{g})$ for $4 \mathrm{~h}$.

Measurement of aminotransferase activity. Serum alanine aminotransferase (ALT) and aspartate aminotransferase (AST) activity was determined using a commercial kit (BioVision, CA, USA). The absorbance was determined using a microplate spectrophotometer (Spectra Max 190, Molecular Device, CA, USA).

RNA isolation and quantitative real-time PCR analysis. Total RNA was extracted with TRIzol Reagent (Invitrogen, CA, USA). cDNA was synthesized using a TOPscript ${ }^{m}$ cDNA Synthesis Kit (Enzynomics, Daejeon, Korea). Real-time PCR was performed with SYBR green (Bio-rad, CA, USA) on a StepOnePlus ${ }^{\mathrm{mx}}$ (Applied Biosystems, CA, USA). Gene expression was normalized to the levels of HPRT mRNA, and relative expression levels were calculated according to the $\Delta \triangle C T$ method. Genes were amplified using the primers listed in Supplementary Table 1. CD160 primer was purchased from Bio-rad.

Liver histology. Liver tissue samples were fixed in 10\% neutral-buffered formalin (Biosesang Inc, Korea) and embedded in paraffin wax. Tissue sections $(7 \mu \mathrm{m})$ were stained with hematoxylin and eosin (H\&E) or subjected to terminal deoxynucleotidyl transferase dUTP nick end labeling (TUNEL) staining according to the kit manufacturer's instructions (DeadEnd ${ }^{\mathrm{TM}}$, Promega, WI, USA).

Statistical analyses. All data were presented as the mean \pm standard error (S.E.M.). Statistical significance was determined by unpaired two-tailed $t$-tests, or paired $t$ tests. For survival curves, log-rank (Mantel-Cox) test was performed. Significance was defined as ${ }^{*} p<0.05,{ }^{*} p<0.01$, and ${ }^{* *} p<0.001$. All analyses were performed using Prism 5.0 software (GraphPad Software, Inc., CA, USA).
Reporting summary. Further information on research design is available in the Nature Research Reporting Summary linked to this article.

\section{Data availability}

The authors declare that the data supporting the findings of this study are available within the article, supplementary information files and Source Data, or are available upon reasonable requests to the authors.

Received: 23 May 2018 Accepted: 28 April 2019

Published online: 22 July 2019

\section{References}

1. Anumanthan, A. et al. Cloning of BY55, a novel Ig superfamily member expressed on NK cells, CTL, and intestinal intraepithelial lymphocytes. J. Immunol. 161, 2780-2790 (1998).

2. Fons, P. et al. Soluble HLA-G1 inhibits angiogenesis through an apoptotic pathway and by direct binding to CD160 receptor expressed by endothelial cells. Blood 108, 2608-2615 (2006).

3. Maeda, M. et al. Murine CD160, Ig-like receptor on NK cells and NKT cells, recognizes classical and nonclassical MHC class I and regulates NK cell activation. J. Immunol. 175, 4426-4432 (2005).

4. Gonzalez, L. C. et al. A coreceptor interaction between the CD28 and TNF receptor family members $\mathrm{B}$ and $\mathrm{T}$ lymphocyte attenuator and herpesvirus entry mediator. P Natl Acad. Sci. USA 102, 1116-1121 (2005)

5. Sedy, J. R. et al. B and T lymphocyte attenuator regulates $\mathrm{T}$ cell activation through interaction with herpesvirus entry mediator. Nat. Immunol. 6, 90-98 (2005).

6. Cheung, T. C. et al. Unconventional ligand activation of herpesvirus entry mediator signals cell survival (vol 106, pg 6244, 2009). Proc Natl Acad. Sci. USA 106, 16535-16536 (2009).

7. Harrop, J. A. et al. Antibodies to TR2 (herpesvirus entry mediator), a new member of the TNF receptor superfamily, block T cell proliferation, expression of activation markers, and production of cytokines. J. Immunol. 161, 1786-1794 (1998).

8. Tamada, K. et al. Modulation of T-cell-mediated immunity in tumor and graft-versus-host disease models through the LIGHT co-stimulatory pathway. Nat. Med. 6, 283-289 (2000).

9. Blackburn, S. D. et al. Coregulation of $\mathrm{CD} 8(+) \mathrm{T}$ cell exhaustion by multiple inhibitory receptors during chronic viral infection. Nat. Immunol. 10, 29-37 (2009)

10. Peretz Y. et al. CD160 and PD-1 co-expression on HIV-specific CD8 T cells defines a subset with advanced dysfunction. PLos Pathog. 8, e1002840 (2012).

11. Vigano S. et al. CD160-associated CD8 T-cell functional impairment is independent of PD-1 expression. PLos Pathog. 10, e1004380 (2014).

12. Le Bouteiller, P. et al. Engagement of CD160 receptor by HLA-C is a triggering mechanism used by circulating natural killer (NK) cells to mediate cytotoxicity. Proc. Natl Acad. Sci. USA 99, 16963-16968 (2002).

13. Bendelac, A. \& Schwartz, R. H. CD4+ and CD8+ T cells acquire specific lymphokine secretion potentials during thymic maturation. Nature 353, 68-71 (1991).

14. Godfrey, D. I., MacDonald, H. R., Kronenberg, M., Smyth, M. J. \& Van Kaer, L. NKT cells: what's in a name? Nat. Rev. Immunol. 4, 231-237 (2004)

15. Bendelac, A., Savage, P. B. \& Teyton, L. The biology of NKT cells. Annu Rev. Immunol. 25, 297-336 (2007).

16. Van Kaer, L. a-Galactosylceramide therapy for autoimmune diseases: prospects and obstacles. Nat. Rev. Immunol. 5, 31-42 (2005).

17. Brossay, L. et al. CD1d-mediated recognition of an alpha-galactosylceramide by natural killer $\mathrm{T}$ cells is highly conserved through mammalian evolution. J. Exp. Med. 188, 1521-1528 (1998).

18. Kawano, T. et al. CD1d-restricted and TCR-mediated activation of valpha14 NKT cells by glycosylceramides. Science 278, 1626-1629 (1997).

19. Watarai, H., Nakagawa, R., Omori-Miyake, M., Dashtsoodol, N. \& Taniguchi, M. Methods for detection, isolation and culture of mouse and human invariant NKT cells. Nat. Protoc. 3, 70-78 (2008).

20. Godfrey, D. I., Stankovic, S. \& Baxter, A. G. Raising the NKT cell family. Nat. Immunol. 11, 197-206 (2010)

21. Savage, A. K. et al. The transcription factor PLZF directs the effector program of the NKT cell lineage. Immunity 29, 391-403 (2008).

22. Lee, Y. J., Holzapfel, K. L., Zhu, J., Jameson, S. C. \& Hogquist, K. A. Steadystate production of IL-4 modulates immunity in mouse strains and is determined by lineage diversity of iNKT cells. Nat. Immunol. 14, 1146-1154 (2013). 
23. Matsumoto, H. et al. Coincidence of autoantibody production with the activation of natural killer $\mathrm{T}$ cells in alpha-galactosylceramide-mediated hepatic injury. Immunology 133, 21-28 (2011).

24. Paget, C. et al. Interleukin-22 Is produced by invariant natural killer T lymphocytes during influenza A virus infection potential role in protection against lung epithelial damages. J. Biol. Chem. 287, 8816-8829 (2012).

25. Cerundolo, V., Silk, J. D., Masri, S. H. \& Salio, M. Harnessing invariant NKT cells in vaccination strategies. Nat. Rev. Immunol. 9, 28-38 (2009).

26. Iwata, A. et al. Protective roles of B and T lymphocyte attenuator in NKT cellmediated experimental hepatitis. J. Immunol. 184, 127-133 (2010).

27. Leite-De-Moraes, M. C. et al. Fas/Fas ligand interactions promote activationinduced cell death of NK T lymphocytes. J. Immunol. 165, 4367-4371 (2000).

28. Uldrich, A. P. et al. NKT cell stimulation with glycolipid antigen in vivo: costimulation-dependent expansion, Bim-dependent contraction, and hyporesponsiveness to further antigenic challenge. J. Immunol. 175, 3092-3101 (2005).

29. Vincent, M. S. et al. CD1-dependent dendritic cell instruction. Nat. Immunol. 3, 1163-1168 (2002).

30. Wang, J. X. et al. Cutting edge: CD28 engagement releases antigen-activated invariant NKT cells from the inhibitory effects of PD-1. J. Immunol. 182, 6644-6647 (2009).

31. Zaini, J. et al. OX40 ligand expressed by DCs costimulates NKT and CD4+ Th cell antitumor immunity in mice. J. Clin. Investig. 117, 3330-3338 (2007)

32. Horney, J. T. \& Galambos, J. T. The liver during and after fulminant hepatitis. Gastroenterology 73, 639-645 (1977).

33. Boyer, J. L. The diagnosis and pathogenesis of clinical variants in viral hepatitis. Am. J. Clin. Pathol. 65, 898-908 (1976).

34. Kumar, V. NKT-cell subsets: Promoters and protectors in inflammatory liver disease. J. Hepatol. 59, 618-620 (2013).

35. Giustiniani, J., Marie-Cardine, A. \& Bensussan, A. A soluble form of the MHC class I-specific CD160 receptor is released from human activated NK lymphocytes and inhibits cell-mediated cytotoxicity. J. Immunol. 178, 1293-1300 (2007).

36. Tu, T. C. et al. CD160 is essential for NK-mediated IFN-gamma production. J. Exp. Med. 212, 415-429 (2015).

37. Cai, G. F. et al. CD160 inhibits activation of human CD4(+) T cells through interaction with herpesvirus entry mediator (vol 9, pg 176, 2008). Nat. Immunol. 9, 567-567 (2008).

38. Harrop, J. A. et al. Herpesvirus entry mediator ligand (HVEM-L), a novel ligand for HVEM/TR2, stimulates proliferation of T cells and inhibits HT29 cell growth. J. Biol. Chem. 273, 27548-27556 (1998).

39. Wang, Y. et al. The role of herpesvirus entry mediator as a negative regulator of T cell-mediated responses. J. Clin. Investig. 115, 711-717 (2005).

40. Watanabe, N. et al. BTLA is a lymphocyte inhibitory receptor with similarities to CTLA-4 and PD-1. Nat. Immunol. 4, 670-679 (2003).

41. Miller, M. L., Sun, Y. L. \& Fu, Y. X. Cutting edge: B and T lymphocyte attenuator signaling on NKT cells inhibits cytokine release and tissue injury in early immune responses. J. Immunol. 183, 32-36 (2009).

42. Wang, J. et al. The regulation of $\mathrm{T}$ cell homeostasis and autoimmunity by $\mathrm{T}$ cell-derived LIGHT. J. Clin. Investig. 108, 1771-1780 (2001).

43. Wahl, C., Wegenka, U. M., Leithauser, F., Schirmbeck, R. \& Reimann, J. IL-22dependent attenuation of $\mathrm{T}$ cell-dependent (ConA) hepatitis in herpes virus entry mediator deficiency. J. Immunol. 182, 4521-4528 (2009).

44. Sedy, J. R. et al. CD160 activation by herpesvirus entry mediator augments inflammatory cytokine production and cytolytic function by NK cells. J. Immunol. 191, 828-836 (2013).
45. Paget, C. et al. Activation of invariant NKT cells by toll-like receptor 9stimulated dendritic cells requires type I interferon and charged glycosphingolipids. Immunity 27, 597-609 (2007).

\section{Acknowledgements}

We thank the NIH Tetramer Core Facility for providing PBS 57 ligand loaded CD1d Tetramers. Further, we thank the staffs of Gyerim Experimental Animal Resource Center for animal care and technical assistance. K.-M. Lee was supported by the Basic Science Research Program through the National Research Foundation of Korea (NRF) funded by the Ministry of Science, ICT, and Future planning (NRF-2016M3A9B6948342, NRF2017R1A2B3004828, and NRF-2018M3A9D3079288). S.-J. Kim was supported by the Korea Health Industry Development Institute (KHIDI-HI14C2640) grant funded by Korea Government. S.-J. Ha was supported by a grant from the NRF (NRF-

2018R1A2A1A05076997). T.-J. Kim was additionally supported by a grant from the NRF (NRF-2016R1A6A3A04009698).

\section{Author contributions}

Conception and design of the study: T.-J.K., G.P., S.-J.H., K.-M.L. Generation, collection, assembly, analysis and/or interpretation of data: T.-J.K., G.P., J.M.K., SA.L., M.H.S., Y.-X. F., S.-J.K., S.-J.H., K.-M.L. Drafting or revision of the manuscript: T.-J.K., G.P., J.K., K.I., J.-I.R., M.-L.D, K.-S.S, C.Y., K.-M.L. Approval of the final version of the manuscript: T.-J. K., K.-M.L.

\section{Additional information}

Supplementary Information accompanies this paper at https://doi.org/10.1038/s41467 019-10320-y.

Competing interests: The authors declare no competing interests.

Reprints and permission information is available online at http://npg.nature.com/ reprintsandpermissions/

Peer review information: Nature Communications thanks the anonymous reviewer(s) for their contribution to the peer review of this work.

Publisher's note: Springer Nature remains neutral with regard to jurisdictional claims in published maps and institutional affiliations.

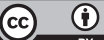

Open Access This article is licensed under a Creative Commons Attribution 4.0 International License, which permits use, sharing, adaptation, distribution and reproduction in any medium or format, as long as you give appropriate credit to the original author(s) and the source, provide a link to the Creative Commons license, and indicate if changes were made. The images or other third party material in this article are included in the article's Creative Commons license, unless indicated otherwise in a credit line to the material. If material is not included in the article's Creative Commons license and your intended use is not permitted by statutory regulation or exceeds the permitted use, you will need to obtain permission directly from the copyright holder. To view a copy of this license, visit http://creativecommons.org/ licenses/by/4.0/.

(C) The Author(s) 2019 